\title{
Modern diagnostic and therapeutic approaches in familial maculopathy with reference to North Carolina macular dystrophy
}

\author{
Jana Nekolova ${ }^{a}$, Alexandr Stepanov ${ }^{a}$, Bohdan Kousal ${ }^{b, c}$, Marketa Stredovaa ${ }^{a}$ Nada Jiraskova ${ }^{a}$
}

\begin{abstract}
Aims. We present a familial hereditary macular dystrophy, resembling North Carolina Macular Dystrophy. In members of a family, we describe the development of diagnostic-therapeutic approaches and their impact on the prognosis of those whose vision was affected.

Methods. The macular dystrophy of varying degrees of severity was diagnosed in 3 consecutive generations in different family members, both men and women. Modern therapeutic tools were used for the diagnostics. In one patient of the youngest generation, the development of secondary choroidal neovascularization (CNV) was identified and treated with an anti-VEGF (vascular endothelial growth factor) agent. DNA was isolated from venous blood and genome sequencing was performed in a proband.

Results. We analysed the data of 13 members of one family of three consecutive generations. Six of them had macular dystrophy. The first were two of three siblings, a woman (73 years old) and a man (67). The offspring of the afflicted man, a female (36) and a male (80), had maculopathy. The first daughter of the woman (12) revealed findings of maculopathy but with normal electrical activity of the retina. The second girl (18), developed secondary CNV which responded well to intravitreal anti-VEGF treatment. Genetic analysis excluded mutations previously reported to be pathogenic for NCMD. Conclusion. If there is a maculopathy of unclear etiology in younger patients or in patients with unclear development or appearance, it is advisable to focus carefully on the family history and trace the occurrence of impaired vision in other family members.
\end{abstract}

Key words: familial maculopathy, North Carolina Macular Dystrophy, anti-VEGF treatment

Received: March 3, 2021; Revised: June 3, 2021; Accepted: June 8, 2021; Available online: June 22, 2021

https://doi.org/10.5507/bp.2021.037

(c) 2022 The Authors; https://creativecommons.org/licenses/by/4.0/

${ }^{a}$ Department of Ophthalmology, University Hospital Hradec Kralove and Faculty of Medicine in Hradec Kralove, Charles University in Prague, Czech Republic

${ }^{b}$ Department of Ophthalmology, First Faculty of Medicine, Charles University and General University Hospital in Prague, Prague, Czech Republic

'Research Unit for Rare Diseases, Department of Pediatrics and Adolescent Medicine, First Faculty of Medicine, Charles University and General University Hospital in Prague, Prague, Czech Republic

Corresponding author: Jana Nekolova, e-mail:janineko@email.cz

\section{INTRODUCTION}

Hereditary macular dystrophies are a heterogeneous group of congenital diseases of the macula which manifest as bilateral involvement with variable onset but most often between 10 and 30 years of age $\mathrm{e}^{1,2}$. All types of inheritance of these diseases have been found: autosomal dominant or recessive, $\mathrm{X}$-linked and mitochondrial, with varying degrees of gene penetration. They are relatively rare, the diagnostics is poorly described and hence there is often a phenotype-based classification that remains unsatisfactory ${ }^{2}$. Further, the classification of macular dystrophies is inconsistent and evolves with further knowledge in the field. The macula is affected by atrophy, deposition of pathological material, and/or the development of pathological secondary choroidal neovascularization (CNV). One consequence is often a decrease in central visual acuity as the main handicap in these patients. The most common macular dystrophies are Best and Stargardt's diseases, autosomal dominant drusen with macular degeneration, various types of macular grid dystrophy, as well as central areolar choroidal macular dystrophy or North Carolina Macular Dystrophy (NCMD). The latter is a rare genetically linked disease characterized by bilateral and often relatively symmetric maculopathy. This dystrophy may be complicated by the development of choroidal neovascularization and accompanied by a significant decrease in visual acuity while the disease itself is often stable or not progressive with a peak deterioration around 12 years of age. It was first reported by Lefler, Wadsworth, and Sidbury in a family originating in Ireland and who settled in the mountains of North Carolina, United States, in the early 1800s, when the authors observed in addition to maculopathy, the occurrence of aminoaciduria in some members of the family ${ }^{3}$. The heredity is autosomal dominant but can take different forms in individual family members. Traditionally, it is classified as three grades. Grade I consists of drusen-like deposits and retinal pigment epithelium (RPE) mottling in the parafoveal area. Grade II consists of confluent drusen, RPE atrophy and disciform scarring of the macula and grade III is severe chorioretinal atrophy of the macula which may appear 
similar to chorioretinal coloboma or staphyloma ${ }^{4}$. Other congenital macular diseases are rarer.

Due to the examination and imaging technologies which are now available, the possibility of genetic testing and better communication between patient and physician, the diagnosis of macular pathologies is easier than in the past. It is not difficult to trace other family members who suffer from the same disease. Advanced therapy is currently available and treat pathologies that would otherwise lead to poor vision and handicap the patient's life. However, despite all the progress, it is not always possible to make a clear diagnosis.

The aim of this article was to present familial hereditary macular dystrophy (HMD) most resembling NCMD, which has not been confirmed by genetic testing and for which no causative gene has not been found yet. Through the members of this family, we will demonstrate the development of modern diagnostic-therapeutic methods and their impact on the prognosis of vision in those affected.

\section{MATERIALS AND METHODS}

This is a family in which we diagnosed macular dystrophy of varying degrees of severity in 3 consecutive generations in different family members, both men and women. Modern technologies including optical coherence tomography (OCT), OCT angiography (OCTA), fluorescent angiography (FA), and electrophysiological examination were used in the diagnosis. Visual acuity of the patients was always tested using Snellen charts or ETDRS optotypes and intraocular pressure was measured noninvasively. The anterior segment and then the posterior segment in artificially dilated pupil were examined. Optical coherence tomography was performed on a Cirrus HD-OCT Model 4000 (Carl Zeiss, Germany) and Heidelberg Spectralis (Spectralis HRA; Heidelberg Engineering, Heidelberg, Germany), where the central retinal thickness was measured and anatomical ratios were calculated. Sodium fluorescein $100 \mathrm{mg} / \mathrm{mL}$ was administered intravenously for FA and fundus images were taken on a Zeiss Visucam 500 cameras. OCT angiography was performed with a Heidelberg-Engineering Spectralis OCT (Spectralis HRA; Germany). Colour vision was examined in a Lanthony D-15 saturated and desaturated assay.

Assessment of reaction and hence retinal function in selected individuals was performed non-invasively and objectively using an electroretinogram. Retinal activity was tested electrophysiologically by a full-field ERG stimulating. All ERGs were measured according to the ISCEV standards ${ }^{5}$. Scotopic and maximal retinal activity were measured after 20 min dark adaptation as well as photopic retinal activity, oscillation potential and $50 \mathrm{~Hz}$ flicker after 5 min light adaptation. The measurements were performed in artificial mydriasis, all using a Roland Consult Science Tool Reti-scan. The central retinal function was also measured using the multifocal electroretinography mode on the same instrument. To obtain partial retinal reactions, a bright image composed of many hexagons was presented on the monitor screen. When measuring, the brightness of each hexagon was monitored by a binary function that was associated with each hexagon. Based on the binary sequence over time, a series of images was created, each image consisting of a combination of black and white hexagons. The result was a flashing stimulus that was composed of different images at each step. The size of the hexagons was set with respect to the retinal sensitivity (in the centre these are $4 \mathrm{X}$ smaller than at the periphery). The total stimulated field was approximately 30 degrees. Responses to stimuli were sensed using electrodes located on the cornea of the patient's eye. The active electrodes were of the DTL type located below the pupil of both eyes. The signal obtained was a summarised mixture of all responses obtained from each stimulated area of the retina. Noise was minimised by averaging the results of many recording cycles and a specialised $50 \mathrm{~Hz}$ smoothing frequency filter. Appropriate electrodes were attached to the patient. The patient's skin was properly cleaned and degreased prior to electrode application. Cup electrodes were used as ground and reference electrodes and placed on the forehead and on the temples. Impedances of reference and DTL electrodes were below $5 \mathrm{k} \Omega$ and below $10 \mathrm{k} \Omega$ for the ground electrode. Patient was placed in front of the monitor so that the eyes were centred on the screen. Electrooculography was then used to exclude morbus Best.

Genetic testing was performed at the Research Unit for Rare Diseases, Department of Pediatrics and Adolescent Medicine, First Faculty of Medicine, Charles University and General University Hospital in Prague. DNA from the three individuals (P.4-6) was extracted from venous blood using Gentra Puregene blood kit (Qiagen, Hilden, Germany) and the proband (P.4) underwent genome sequencing. It was analysed by genome sequencing using a TruSeq Nano DNA library preparation kit and a HiSeq X Ten sequencer (Illumina, Inc., San Diego, CA, USA). FASTQ reads were aligned to the GRCh38/hg 38 human reference sequence using the Burrows-Wheeler Alignment tool ${ }^{6}$. Variant calling was performed with HaplotypeCaller ${ }^{7}$. Sequencing data were visualized with the Integrated Genomics Viewer (IGV) (Broad institute, California, USA) (ref. ${ }^{8}$ ).

The population frequency of the identified variants was retrieved from the Genome Aggregation Database (gnomAD v3.1), providing whole genome sequencing data of 76,156 unrelated individuals of various ethnic backgrounds ${ }^{9}$. Known loci implicated in the pathogenesis of NCMD (chromosome 5p15-p13 and chromosome 6q16) (ref. ${ }^{10}$ ) were prioritized based on the phenotype and further investigated for the presence of likely pathogenic variants.

In one patient of the youngest generation (P.6), the development of secondary CNV (type 2 of macular neovascularization according to the classification of macular neovascularizations from the Consensus published by Spaide ${ }^{11}$ ), which responded well to anti-VEGF treatment with ranibizumab $0.5 \mathrm{mg}$ in $0.05 \mathrm{~mL}$, was recorded. The treatment was carried out in the pro re-nata $(\mathrm{PRN})$ regimen, ie the first three monthly injections were followed by controls, evaluating signs of CNV activity by OCT (intra 
and subretinal fluid, RPE ablation). The patient improved significantly after the first three doses and no signs of CNV activity were noted. The results of this therapy have been carefully monitored.

\section{RESULTS}

In total, ocular data from 13 members of one family of 3 consecutive generations were analysed, 6 of whom, 2 men and 4 women, were shown to be afflicted with macular dystrophy. The first identified patients were two of three siblings, a woman ( 73 years old) and a man (67 years old). Their middle brother, 69 years old, was demonstrably not affected. Descendants of the woman and her children were also not demonstrably affected. On the other hand, the offspring of the affected man, a woman (36 years old) and a man (40 years old), had pathological findings in the macula. The sons of the man refused to attend the examinations, while the daughters of the woman were tested in detail, including using electrophysiological methods.

Patient 1, a female, 73 years old, was observed for retinal dystrophy from 6 years of age, her vision deteriorated after whooping cough, and her visual acuity decreased further after delivery and after menopause. At the last examination in 2019 , the best corrected visual acuity of the right eye was 20/50 and the left eye was 20/160 4x.
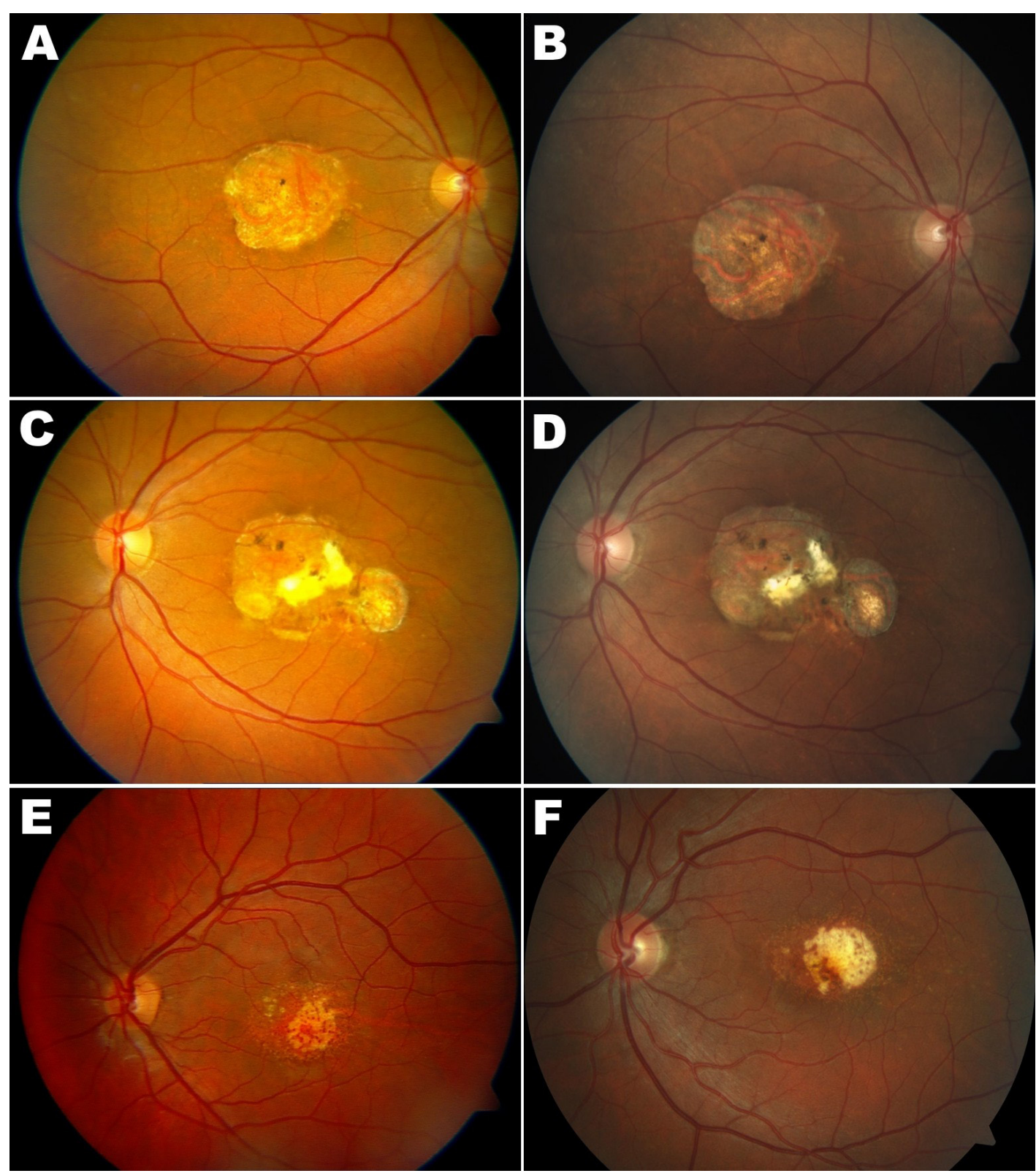

Fig.1 A-D. Patient 1. The fundoscopy revealed large bilateral lesions of the RPE affecting the macular area, long-term stable findings, worse left eye. 1A. right eye 15 years before and 1B. right eye, current finding. 1C. left eye 15 years before and 1D. left eye, current finding. 1E. Patient 3. Fundus photography of the left eye. Beaten- bronze-like pigment changes in the macula. 1F. Patient 4. Fundus photography of the left eye. Yellowish-white foci encircled by hypopigmented halos in the macula, surrounded by hyperpigmentation. 


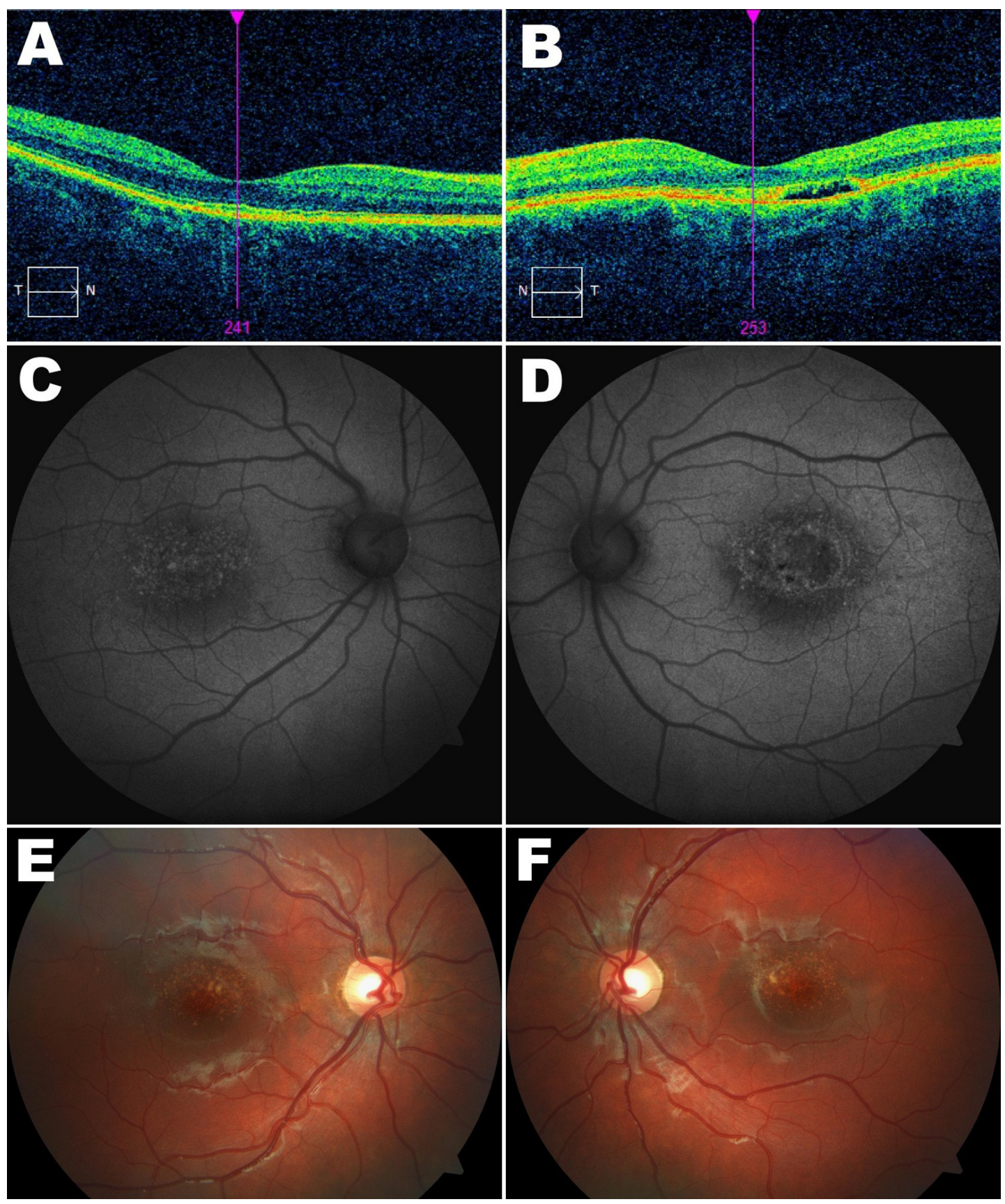

Fig. 2.A-D Patient 4. 2A. OCT of the right eye: foveal depression is present, focal RPE damage. 2B. OCT of the left eye: focal neurosensory detachment, area of the RPE damage. 2C. (Right eye) and 2D. (Left eye) FAF: The focal increased pattern with several well-defined spots with markedly increased FAF surrounded by a halo of decreased FAF. 2E-F. Patient 5. Fundus photography, non-volatile yellowish-white lesions in the macula. 2E. Right eye. 2F. Left eye.

The fundoscopy revealed large bilateral lesions of the RPE affecting the macular area completely. Comparing the available photodocumentation, this was a long-term stable finding, without progression over time (Fig. 1 A-D). Both the children of the patient and their children had no signs of retinal dystrophy.

Patient 2, a male, 67 years old, had a long-term stable finding of maculopathy of the appearance of RPE defects but his visual acuity remains normal. His children were affected (patient 3 and 4).

Patient 3 , a male, age of 40 , with normal visual acuity, but findings in the macula with beaten- bronze-like pigment changes were evident which are invariant over time (Fig. 1 E). His two sons also had no visual impairments. They did not attend the fundus examination in mydriasis.

Patient 4, a female, 36 years old, had yellowish-white foci encircled by hypopigmented halos in the macula, more in the left eye, where the focal point was about $1 \mathrm{pu}-$ pillary diameter, surrounded by hyperpigmentation. The other retina showed no pathologies, visual acuity was normal (Fig. 1 F, Fig. 2 A-D). Her daughters were affected.

Patient 5, a girl, 12 years old, was examined for the finding of maculopathy with individual non-volatile yel- 

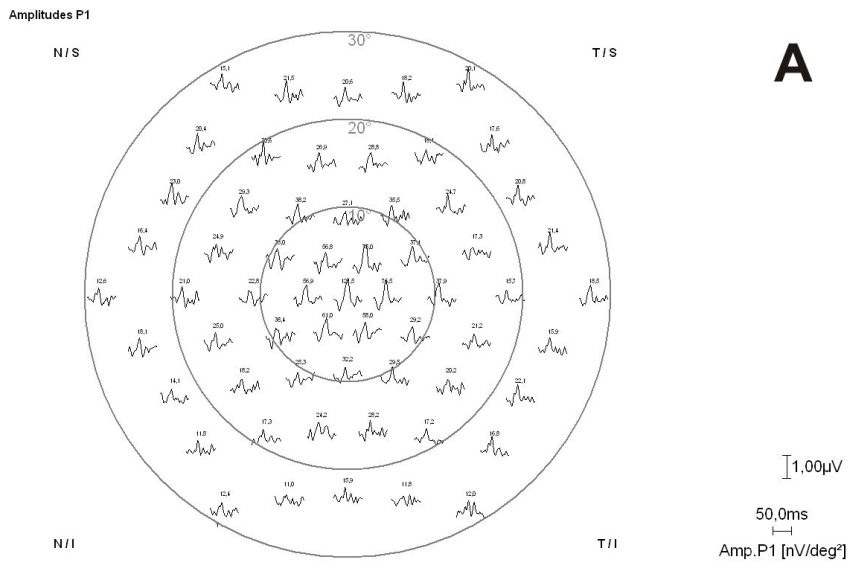

3D Amplitudes P1
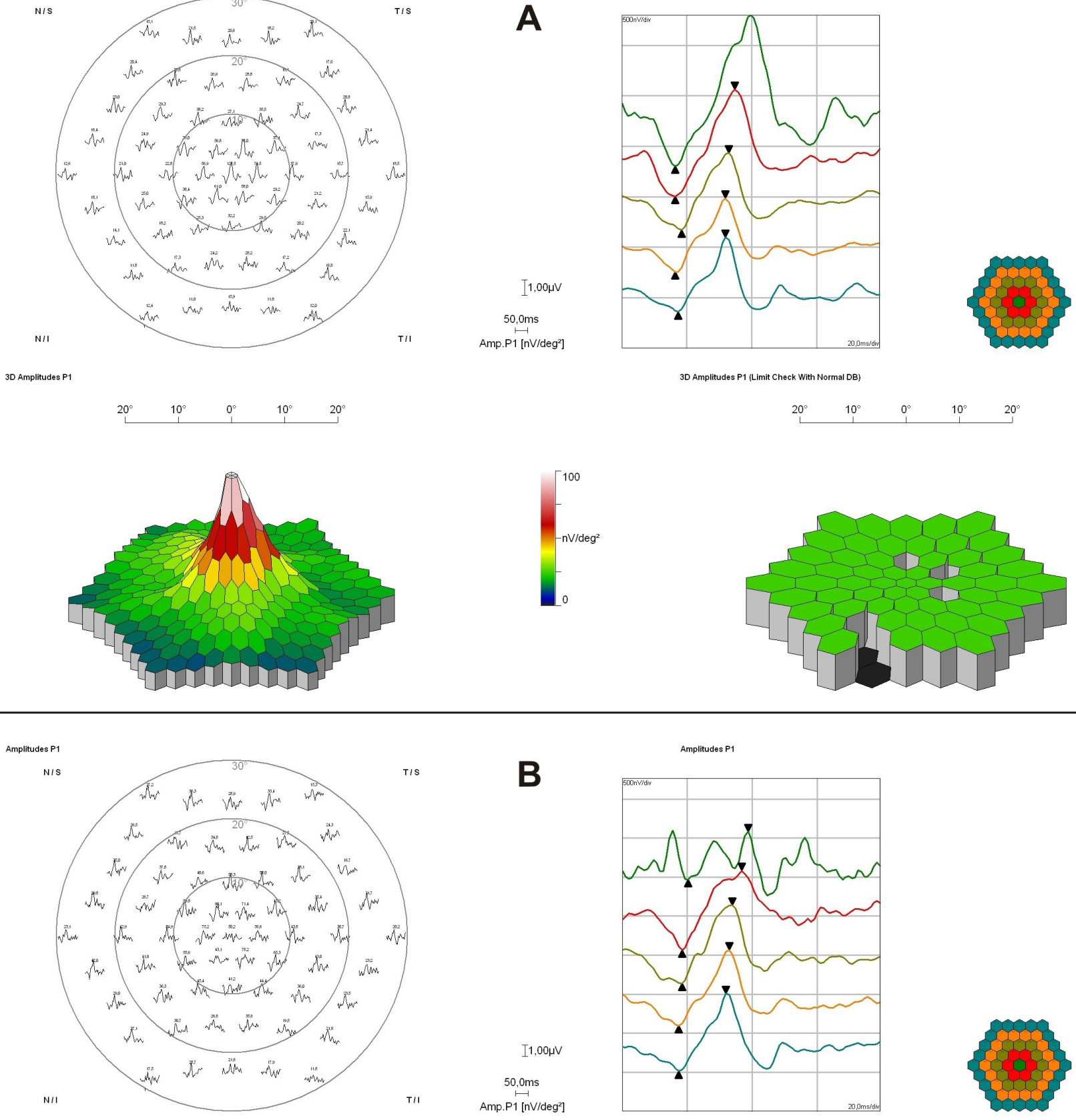

3D Amplitudes $\mathrm{P} 1$

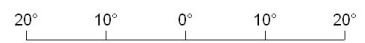
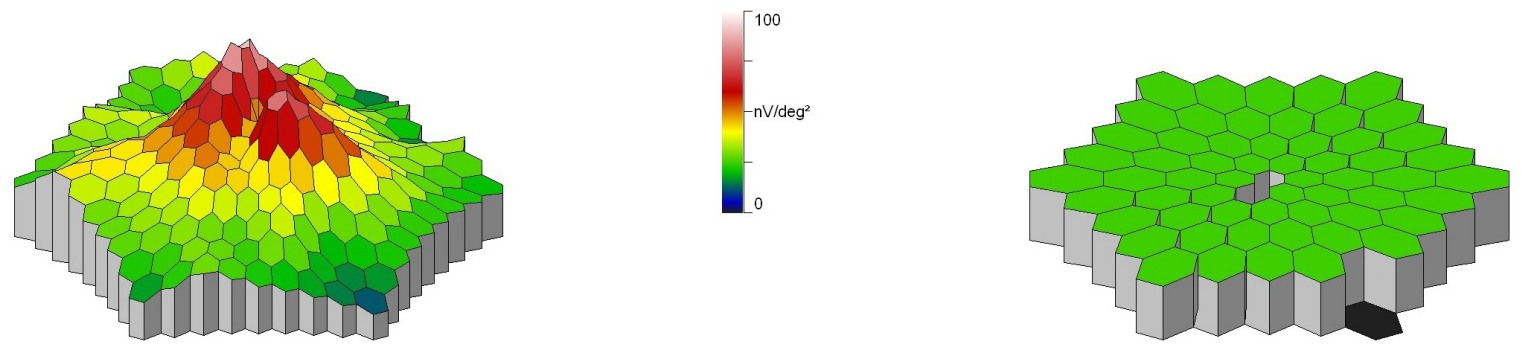

Fig. 3A-B. Patient 6. 3A. Multifocal ERG (mfERG) of the right eye, normal local and average responses. 3B. MfERG of the left eye before treatment, foveal area showed decreased responses (foveal activity was $40 \%$ of the laboratory standard), the others responses were unaffected. 


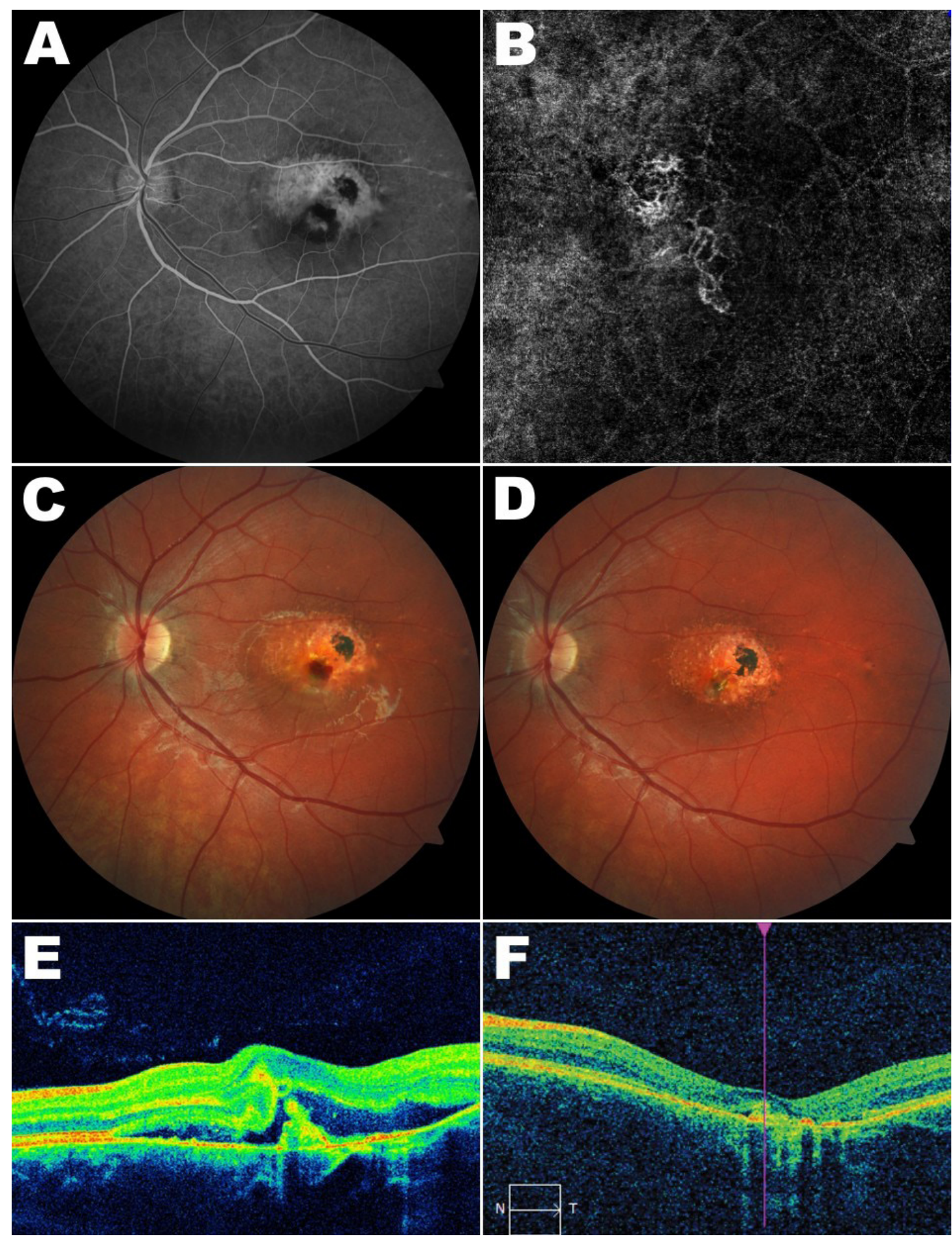

Fig. 4 A-F. Patient 6. 4A. Fluorescein angiography (FA) of the left eye, arteriovenous phase: gradually increasing hyperfluorescence due to classical submacular neovascularization in the lower part of the macula, blockade of fluorescence due to hemorrhages around the lesion, pooling of neuroretinal ablations, window defects of RPE. 4B. OCT angiography of the left eye, Type 2 of CNV in the avascular layer of the neuroretina. 4C. Fundus photography of the left eye. Circular plaques of coalescing yellowish-white masses, hypopigmented halos in the vicinity, gross pigment deposits and area of RPE atrophy with sub-macular haemorrhage due to CNV. 4D. Fundus photography of the left eye after treatment. Disappearance of the submacular haemorrhage, improvement. 4E. OCT of the left eye before treatment, OCT scan shows an inaccurately delineated lesion of mixed moderate reflectivity in the lower part of the macula with serous parafoveal neurosensory detachment, area of the RPE damage and 4F. improvement after antiVEGF therapy. 
lowish-white lesions, with RPE structural changes and atrophy, which were detected during routine preventive examination (Fig. 2 E-F). However, her visual acuity as well as the electrical activity of the retina were normal.

Patient 6, a girl, 18 years old, was one of the most affected of the family. In her macula, bilateral paler deposits with dot-like RPE changes were detected as early as one year of life. However, the patient had preserved visual acuity. Due to the maculopathy, she was referred for examination to our clinic at her age of 15 years. A week before the examination, she reported a gradual decrease of the visual acuity of the left eye and metamorphopsia. Her visual acuity was 20/20 of the right eye and 20/80 of the left eye. The fundus autofluorescence showed a focal increased pattern with several well-defined spots with markedly increased FAF surrounded by a halo of decreased FAF. Normal retinal electrical activity (ERG, electrooculography) was measured by electrophysiological methods, there were decreased responses in the multifocal ERG of the left foveal area; the left foveal activity was $40 \%$ of the laboratory standard, the others average and local responses were unaffected (Fig. 3). We performed OCT, FA and OCTA examinations. During FAG of the right eye there were window defects of RPE, no signs of leakage and in the left eye, there was gradually increasing hyperfluorescence due to classical submacular neovascularization in the lower part of the macula, blockage of fluorescence due to hemorrhages around the lesion, pooling of neuroretinal ablations, window defects of RPE (Fig. 4 A). OCT angiography of the left eye demonstrated type $2 \mathrm{CNV}$ in the avascular layer of the neuroretina (Fig. 4 B). The findings in the macula were bilateral circular plaques of coalescing yellowish-white masses, in the right eye there was hyperpigmentation in the macula, hypopigmented halos in the vicinity, gross pigment deposits and area of RPE atrophy. In the left eye there was a submacular haemorrhage with retinal oedema and neuroretinal ablation, the mid-periphery of the retina and further was normal (Fig. $4 \mathrm{C}$ ). The finding was concluded as hereditary macular dystrophy v.s. North Carolina, in the left eye complicated by secondary CNV. The patient was then given in total three monthly intravitreal injections of ranibizumab. Visual acuity of the left eye has improved to 20/25 and has remained stable for the entire follow-up period ( 3 years). The anatomical finding according to fundus photography and OCT improved significantly, only the fine ablation of RPE due to scarring CNV remained, neuroretina had no signs of edema, submacular haemorrhage disappeared and the patient's subjective complaints improved (Fig. 4 D). Linear horizontal transfoveolar OCT scan showed a foveal depression and minimal subretinal fluid and RPE damage in the right eye and there was an inaccurately delineated lesion of mixed moderate reflectivity in the lower part of the macula with serous ablation of the neuroretina in the left eye (Fig. 4 E) before treatment which disappeared after 3 injections of ranibizumab (Fig. 4 F). The patient continues to attend our clinic at regular intervals.

Electrooculography was also performed on the patients 4-6 to exclude Best's disease and it was normal in all cases (Arden ratio ranged from 2.1 to 2.6). Colour vision was normal in these individuals. Intraocular pressure was normal in all cases and ranged from 12 to $22 \mathrm{~mm} \mathrm{Hg}$.

The genetic test was negative. No possibly pathogenic variants were identified using the methodology described in Methods section.

\section{DISCUSSION}

Historically, macular dystrophies were defined as a heterogenous group of congenital disorders that have ophthalmoscopically visible abnormalities in the area of the retina center surrounded by temporal vascular arcades ${ }^{12}$. This definition is not sufficient today. Currently, macular dystrophies include diseases that have Mendelian inheritance that are isolated only to the eyes and are observable in the macula. The reasons why some diseases affect only the macula are not clearly defined. It may be related to anatomical differences in density, structure and composition of choriocapillaris, Bruch's membrane, RPE and photoreceptor cells ${ }^{12}$. There are today many known genes causing macular dystrophy but many of them remain undetected. There is also no correlation between clinical findings in carriers of equally affected genes, and similar findings are seen in different genetic mutations. All this beleaguers diagnosis and hence treatment and estimation of prognosis in such affected patients. We encountered similar pitfalls in the individual members of the monitored family. Their phenotype is most reminiscent of the NCMD.

Macular dystrophy of the North Carolina type is a rare genetically linked disease characterized by bilateral and often relatively symmetrical maculopathy. This can impair visual acuity and in advanced stages, lead to the development of choroidal neovascularization and marked decrease in visual acuity. It is an autosomal dominant disease with complete penetration but different expression. The greatest deterioration is between 10-20 years of age $\mathrm{a}^{4}$.

Several types of NCMD are described but data from publications vary. Audere and Small assign MCDR13 to NCMD (ref. ${ }^{10,13-15}$ ), while Michaelides and Moore assign MCDR3 to NCMD-like diseases ${ }^{16}$. None of the MCDR1-3 types have been attributed to any particular gene; there are only linkage data available for the selected loci. Historically MCDR1 (MC- macular, D- dystrophy, Rretinal, 1-first) macular degeneration reliably genetically mapped was analysed more intensively and in a large kindred of 2000 individuals. The genetic locus $6 \mathrm{q} 16$ has been described and it most probably will contain the MCDR1 causative gene ${ }^{17}$. The MCDR2 type is caused by a mutation in the PROM1 gene on chromosome 4p15. North Carolina macular dystrophy exists worldwide and does not emanate from a single family from North Carolina. In 2010, Rosenberg et al. described a family in Scandinavia and performed linkage analysis for ten members of the family ${ }^{18}$. The results overlap with the previously reported 5p13-p15 region for MCDR3 containing more than 55 genes.

In many genetic diseases, changes in the DNA that cause the disease are in genes and they alter the instruc- 
tions for making the protein. However, the pathogenic variations that cause NCMD are probably in the noncoding areas of the DNA. These regions of the DNA may control when the proteins are made from other nearby genes (gene expression) (ref. $\left.{ }^{4}\right)$. It was found that pathogenic variations in the MCDR1 locus are in non-coding regions close to the PRDM13 gene. The protein made from the PDRM13 gene is probably important for development of macula. It is likely that MCDR3 locus is also involved in controlling when other genes are turned on (gene expression). The changes in the MCDR3 locus that cause NCMD may affect the expression of the IRX1 gene ${ }^{19}$. Autosomal dominant macular dystrophy with early development resembling North Carolina, called MCDR3, has been described in a British pedigree ${ }^{20}$. The patient's visual acuity ranged from 20/20 to 20/200. Pathological changes on the retina were limited to the macular area only, from mild pigment changes of RPE to atrophy. Deposits similar to drusen of varying degrees are typical of this phenotype. The described complication was the formation of CNV. EOG and ERG examinations were normal, suggesting that there was no generalised retinal dysfunction. The only significant differences between this phenotype and MCDR1 were that in MCDR3, the colour vision was abnormal in most affected individuals and in one case the disease progressed ${ }^{16}$. A Danish family with a phenotype corresponding to MCDR3 has also been described ${ }^{18}$. In both families, association with MCDR1 was excluded, but binding to chromosome 5p13.1-p15.33 was confirmed ${ }^{18,20}$. The exact gene has not yet been identified ${ }^{16}$.

Another North Carolina-like macular dystrophy is MCDR4, which in addition to typical maculopathy also has progressive sensorineural hearing loss. A family from the United Kingdom was described where the visual acuity ranged from 20/32 to hand motion ${ }^{21}$. Progressive sensorineural deafness was present in all affected individuals over 20 years of age. Genotyping excluded binding to the MCDR1 locus, suggesting binding to chromosome 14q. The last type of North Carolina-like macular dystrophy is the Sorsby syndrome which is accompanied by digital anomalies $^{16}$.

Of these three types of North Carolina-like macular dystrophies described, due to the lack of other congenital anomalies such as finger anomaly or progressive deafness, it would most closely match the first type, MCDR3, although colour vision was not altered in our sample. It is therefore possible that this is another type of North Carolina-like macular dystrophy that has not yet been described in the literature.

There was another macular dystrophy considered in the differential diagnosis- a progressive bifocal chorioretinal atrophy (PBCRA). It is an autosomal dominant retinal dystrophy characterized by large atrophic macular lesions and chorioretinal atrophy nasal to the optic disc. The gene for PBCRA is linked to chromosome $6 \mathrm{q}$, near the genomic assignment for NCMD. Visual acuity in patients with PBCRA did not correlate with the severity of maculopathy; it was better than expected given the extent of affected retina. However, horizontal nystagmoid oscillations, chorioretinal atrophy nasal to the optic disc and pathological ERG described in patients with PBCRA (ref. ${ }^{22}$ ) were not found in the observed family.

In the observed family there were individuals with low-vision impairment (patient 1) but most of the family members achieved satisfactory vision despite extensive changes in the macula. The development of the disease was also different in individual family members, ranging from a stabilised condition in most family members to progressive disease with complications of secondary $\mathrm{CNV}$ in puberty (patient 6).

The most common cause of CNV is age-related macular degeneration, which, if left untreated, leads to a significant decrease in visual acuity in patients over 55 years of age $^{23-26}$. Other causes of CNV include pathological myopia $^{27-29}$, polypoidal choroidal vasculopathy ${ }^{30-32}$, presumed ocular histoplasmosis syndrome ${ }^{33}$, angioid streaks ${ }^{34-35}$, uveitis $^{36}$, choroidal rupture or trauma, central serous chorioretinopathy, macular dystrophy ${ }^{37-40}$ and idiopathic CNV. Choroidal neovascularization for reasons other than AMD and pathological myopia is rare and usually occurs in working-age adults ${ }^{41}$.

NCMD was initially considered to be slowly progressive, but a subsequent review found the condition to be developmental with variable non progressive retinal findings ${ }^{42}$. In rare cases, $\mathrm{CNV}$ can involve developing visual changes in both young ${ }^{10,43}$ and older patients with NCMD (ref. ${ }^{15}$ ). There is only one published case with NCMD with CNV and anti-vascular endothelial growth factor treatment in a 60 -year-old patient ${ }^{44}$. In contrast to this patient at an age typical for the development of AMD, we describe the case of a young patient with a finding of secondary CNV (type 2 of macular neovascularization) who, at age 15 , received 3 injections of ranibizumab at monthly intervals. CNV regression and visual acuity improvement was achieved after the therapy. We have seen a very favorable response to anti-VEGF treatment, when it was not necessary to continue with other applications over the next 3 years though the patient is still regularly followed-up. This is a unique use of anti-VEGF agents in a young patient with a very rare diagnosis and a very favorable result.

Modern diagnostic techniques, including electroretinography and retinal imaging by OCTA, were used to diagnose the macular involvement.

OCTA is a recent non-invasive imaging examination method that has been used in practice since 2015 (ref. $\left.{ }^{45-47}\right)$.

Angiographic information is obtained simultaneously from the retina and choroidal vascular bed without the use of dye. As a contrast, it uses the movement of blood elements and a decorrelation signal between successive OCT b-scans generated in the same section. It allows visualisation of the superficial and deep vascular plexus of the inner layers of the retina originating from the arteria centralis retinae, the outer layer of the retina - the RPE and the photoreceptors and choriocapillaris simultaneously. We had the opportunity to capture different stages of familial maculopathy in individuals, including $\mathrm{CNV}$ 
in one of the girls. There are very few published studies describing the use of OCTA to diagnose this disease, as well as its therapy ${ }^{48}$.

In differential diagnosis, it is necessary to consider other macular dystrophies and focus on genetic testing of known genes for these diseases. The Arden ratio lower than 1.55 is significant for Best vitelliform macular dystrophy, it was higher than 2.0 in this family ${ }^{49}$. No gene described for any macular hereditary disease was found in our sample. In addition, other diseases, such as toxoplasmic maculopathy, have a similar appearance ${ }^{50-51}$. However, it is unlikely that changes in the macula will occur across multiple members of the same family as in our sample.

Despite modern technologies identification of diseasecausing mutation may be a challenge, especially when it comes to non-coding and structural variants. Further research such as expanding genome sequencing to other family members or linkage analysis is necessary to resolve the molecular genetic cause in the family studied.

To further clarify the point on segregation analysis, in the absence of clearly pathogenic variants we are not able to perform it. It is our plan to gain further funding to extend genetic analysis to more members. We think however that this is out of the scope of the current study which is mainly focused on clinical findings.

\section{CONCLUSIONS}

If there is a maculopathy of unclear etiology in younger patients or in patients with unclear development or appearance of macular disease, it is advisable to focus carefully on family history and to trace the occurrence of impaired vision in other family members. When suspected, many auxiliary examinations, including genetic testing, can be used to verify the disease. Despite the fact that there are already many known genes, it is not always possible to find the causative gene, although the disease is demonstrably hereditarily based. Thanks to modern therapeutic technologies it is possible to prevent the negative development of the disease, often resulting in severe vision loss or practical blindness. For patients with inherited macular dystrophy with abnormal macular anatomy and secondary $\mathrm{CNV}$, intravitreal treatment with anti-VEGF can result in significantly improved vision.

Acknowledgements: Supported by the programme PROGRES Q40/07 and by the grant AZVMZ CR NV 18-06-00484. Genetic analysis was supported by the grant NU20-07-00182 from the Ministry of Health of the Czech Republic.

Author contributions: All of authors contributed equally to preparing the manuscript.

Conflict of interest statement: The authors state that there are no conflicts of interest regarding the publication of this article.

\section{REFERENCES}

1. Lang G. Retinal Dystrophies. Ophthalmology, 2nd edition. Germany: Thieme; 2004, p. 354.

2. Michaelides M, Hunt DM, Moore AT. The genetics of inherited macular dystrophies. J Med Genet 2003;40:641-50.

3. Lefler VH, Wadsworth JAC and Sidbury JB. Hereditary macular degeneration and aminoaciduria. Am J Ophthalmol 1971;71:224-30.

4. McKusick VA. North Carolina Macular Dystrophy (Macular Dystrophy of the Retina Locus I), created 1986 Apr 6, updated Bocchini CA 2019 Oct 29, [Internet]. OMIM Entry; Available from: https://www.omim. org/entry/136550.

5. McCulloch DL, Marmor MF, Brigell MG, Hamilton R, Holder GE, Tzekov R, Bach M. ISCEV Standard for full-field clinical electroretinography (2015 update). Doc Ophthalmol 2015;130:1-12.

6. Li H, Durbin R. Fast and accurate long-read alignment with BurrowsWheeler transform. Bioinformatics 2010;26:589-95.

7. Van der Auwera GA, Carneiro MO, Hartl C, Poplin R, Del Angel G, Levy-Moonshine A, Jordan T, Shakir K, Roazen D, Thibault J, Banks E, Garimella KV, Altshuler D, Gabriel S, DePristo MA. From FastQ data to high confidence variant calls: the Genome Analysis Toolkit best practices pipeline. Curr Protoc Bioinformatics 2013;43:11.10.1-11.10.33.

8. Thorvaldsdottir H, Robinson JT, Mesirov JP. Integrative Genomics Viewer (IGV): high-performance genomics data visualization and exploration. Briefings Bioinf 2013;14:178-92.

9. Karczewski KJ, Francioli LC, Tiao G, Cummings BB, Alföldi J, Wang Q, Collins RL, Laricchia KM, Ganna A, Birnbaum DP, Gauthier LD, Brand $H$, Solomonson M, Watts NA, Rhodes D, Singer-Berk M, England EM, Seaby EG, Kosmicki JA, Walters RK, Tashman K, Farjoun Y, Banks E, Poterba T, Wang A, Seed C, Whiffin N, Chong JX, Samocha KE, PierceHoffman E, Zappala Z, O'Donnell-Luria AH, Minikel EV, Weisburd B, Lek M, Ware JS, Vittal C, Armean IM, Bergelson L, Cibulskis K, Connolly KM, Covarrubias M, Donnelly S, Ferriera S, Gabriel S, Gentry J, Gupta N, Jeandet T, Kaplan D, Llanwarne C, Munshi R, Novod S, Petrillo N, Roazen D, Ruano-Rubio V, Saltzman A, Schleicher M, Soto J, Tibbetts K, Tolonen C, Wade G, Talkowski ME; Genome Aggregation Database Consortium, Neale BM, Daly MJ, MacArthur DG. The mutational constraint spectrum quantified from variation in 141,456 humans. Nature 2020;581:434-43.

10. Small KW, DeLuca AP, Whitmore SS, Rosenberg T, Silva-Garcia R, Udar N, Puech B, Garcia CA, Rice TA, Fishman GA, Héon E, Folk JC, Streb LM, Haas CM, Wiley LA, Scheetz TE, Fingert JH, Mullins RF, Tucker BA, Stone EM. North Carolina Macular Dystrophy Is Caused by Dysregulation of the Retinal Transcription Factor PRDM13. Ophthalmology 2016;123(1):9-18.

11. Spaide RF, Jaffe GJ, Sarraf D, Freund KB, Sadda SR, Staurenghi G, Waheed NK, Chakravarthy U, Rosenfeld PJ, Holz FG, Souied EH, Cohen SY, Querques G, Ohno-Matsui K, Boyer D, Gaudric A, Blodi B, Baumal CR, Li X, Coscas GJ, Brucker A, Singerman L, Luthert P, Schmitz-Valckenberg S, Schmidt-Erfurth U, Grossniklaus HE, Wilson DJ, Guymer R, Yannuzzi LA, Chew EY, Csaky K, Monés JM, Pauleikhoff D, Tadayoni R, Fujimoto J. Consensus Nomenclature for Reporting Neovascular Age-Related Macular Degeneration Data. Consensus on Neovascular Age-Related Macular Degeneration Nomenclature Study Group. Ophthalmology 2020;127:616-36.

12. Sohn EH, Mullinns RF, Stone EM. Macular Dystrophies. In: Ryan SJ, editor. Retina 5th ed., Philadelphia:Saunders;2013.p.852-86.

13. Audere M, Rutka K, Inaskina I, Peculis R, Sepetiene S, Valeina S, Lāce B. Genetic linkage studies of a North Carolina macular dystrophy family. Medicina 2016;52(3):180-86.

14. Small KW, Weber JL, Roses A, Lennon F, Vance JM, Pericak-Vance MA. North Carolina macular dystrophy maps to chromosome 6. Genomics 1992;13:681-85.

15. Small KW. North Carolina macular dystrophy: clinical features, genealogy, and genetic linkage analysis. Trans Am Ophthalmol Soc 1998;96:925-61.

16. Michaelides M, Moore A. North Carolina Macular Dystrophy and North Carolina Macular Dystrophy-like Disorders in Querques G, Souied E. Macular Dystrophies, US:Springe;2016. p.55-62.

17. Bowne SJ, Sullivan LS, Wheaton DK, ocke KG, Jones KD, Koboldt DC Fulton RS, Wilson RK, Blanton SH, Birch DG, Daiger SP. North Carolina macular dystrophy (MCDR1) caused by a novel tandem duplication of the PRDM13 gene. Mol Vis 2016;22:1239-47. 
18. Rosenberg T, Roos B, Johnsen T, Bech N, Scheetz TE, Larsen M, Stone EM, Fingert JH. Clinical and genetic characterization of a Danish family with North Carolina macular dystrophy. Mol Vis 2010;16:2659-68.

19. North Carolina macular dystrophy. [Internet]. Genetic and Rare Disease Information Center.Available from: https://rarediseases. info.nih.gov/diseases/9179/north-carolina-macular-dystrophy.

20. Michaelides M, Johnson S, Tekriwal AK, Holder GE, Bellmann C, Kinning E, Woodruff G, Trembath RC, Hunt DM, Moore AT. An earlyonset autosomal dominant macular dystrophy (MCDR3) resembling North Carolina macular dystrophy maps to chromosome 5. Invest Ophthalmol Vis Sci 2003;44(5):2178-83.

21. Franics PJ, Johnson S, Edmunds B, Kelsell RE, Sheridan E, Garrett $C$, Holder GE, Hunt DM, Moore AT. Genetic linkage analysis of a nove syndrom comprising North Carolina-like macular dystrophy and progressive sensorineural hearing loss. Br J Ophthalmol 2003;87(7):89398.

22. Godey BF, Tiffin PAC, Evans K, Kelsell RE, Hunt DM, Bird AC. Clinical Features of Progressive Bifocal Chorioretinal Atrophy. A retinal dys trophy linked to Chromosome 6q. Ophthalmology 1996;103(6):89398.

23. Klein R, Chou CF, Klein BE, Zhang X, Meuer SM, Saaddine JB. Prevalence of age-related macular degeneration in the US population. Arch Ophthalmol 2011;129(1):75-80.

24. Heiferman MJ, Fawzi AA. Progression of subclinical choroidal neovascularization in age-related macular degeneration. PLoS One 2019;14(6):e0217805.

25. Stavrev VN, Sivkova NP, Koleva-Georgieva DN. Optical Coherence Tomography-Angiography of Different Choroidal Neovascularization Subtypes in Wet Age-related Macular Degeneration. Folia Med (Plovdiv) 2019;61(2):317-26.

26. Bae K, Kim HJ, Shin YK, Kang SW. Predictors of neovascular activity during neovascular age-related macular degeneration treatment based on optical coherence tomography angiography. Sci Rep 2019;9(1):19240.

27. Ohno-Matsui K, Ikuno Y, Lai TYY, Gemmy Cheung CM. Diagnosis and treatment guideline for myopic choroidal neovascularization due to pathologic myopia. Prog Retin Eye Res 2018;63:92-106.

28. Pascual-Camps I, Andreu-Fenoll M, Ruiz-Moreno JM, Dolz-Marco R, Gallego-Pinazo R. Prognostic Tomographic Classification of Myopic Choroidal Neovascularization. Ophthalmic Surg Lasers Imaging Retina 2018;49(10):775-79.

29. Cheung CMG, Arnold JJ, Holz FG, Park KH, Lai TYY, Larsen M, Mitchell P, Ohno-Matsui K, Chen SJ, Wolf S, Wong TY. Myopic Choroida Neovascularization: Review, Guidance, and Consensus Statement on Management. Ophthalmology 2017;124(11):1690-711.

30. Gu X, Yu X, Dai H. Therapeutic effects of ranibizumab in patients with polypoidal choroidal vasculopathy. BMC Ophthalmol 2019;19(1):153.

31. Dansingani KK, Gal-Or O, Sadda SR, Yannuzzi LA, Freund KB. Understanding aneurysmal type 1 neovascularization (polypoida choroidal vasculopathy): a lesson in the taxonomy of 'expanded spectra' - a review. Clin Exp Ophthalmol 2018;46(2):189-200.

32. Cheung CMG, Lai TYY, Ruamviboonsuk $P$, Chen SJ, Chen $Y$ Freund KB, Gomi F, Koh AH, Lee WK, Wong TY. Polypoidal Choroidal Vasculopathy: Definition, Pathogenesis, Diagnosis, and Management. Ophthalmology 2018;125(5):708-24.

33. Blinder KJ. Management of neovascular ocular histoplasmosis: Past and Present Retina 2019;39(2):226-34.

34. Makri OE, Tsapardoni FN, Plotas P, Pallikari A, Georgakopoulos CD. Intravitreal aflibercept for choroidal neovascularization secondary to angioid streaks in a non-responder to intravitreal ranibizumab. Int Med Case Rep J 2018;11:229-31.

35. Chatziralli I, Saitakis G, Dimitriou E, Chatzirallis A, Stoungioti S Theodossiadis G, Theodossiadis P. Angioid streaks: A Comprehensive Review from Pathophysiology to Treatment. Retina 2019;39(1):1-11.

36. Wang JC, McKay KM, Sood AB, Laíns I, Sobrin L, Miller JB. Comparison of choroidal neovascularization secondary to white dot syndromes and age-related macular degeneration by using optical coherence tomography angiography. Clin Ophthalmol 2018;13:95-105.

37. Murro V, Mucciolo DP, Giorgio D, Sodi A, Passerini I, Virgili G, Rizzo S. OCTA Imaging of Choroidal Neovascularization Treated Using Photodynamic Therapy in a Young Patient With Best Macular Dystrophy. Ophthalmic Surg Lasers Imaging Retina 2018;49(12):96973.

38. Battaglia Parodi M, Romano F, Marchese A, Arrigo A, Llorenç V, Cicinelli MV, Bandello F, Adán A. Anti-VEGF treatment for choroidal neovascularization complicating pattern dystrophy-like deposit associated with pseudoxanthoma elasticum. Graefes Arch Clin Exp Ophthalmol 2019;257(2):273-78.

39. Gulkilik G, Erdur SK, Eliacik M, Odabasi M, Ozsutcu M, Demirci G, Kocabora MS. A case of cone dystrophy associated with choroidal neovascularization. Retin Cases Brief Rep 2018;12(2):111-14.

40. Kobat SG, Gul FC, Yusufoglu E. Bietti crystalline dystrophy and choroidal neovascularization in childhood. Int J Ophthalmol 2019;12(9):1514-16.

41. Cohen SY, Laroche A, Leguen Y, Soubrane G, Coscas GJ. Etiology of choroidal neovascularization in young patients. Ophthalmology 1996;103(8):1241-44.

42. Small KW. North Carolina macular dystrophy, revisited. Ophthalmology 1989;96:1747-54.

43. Rhee DY, Reichel E, Rogers A, Strominger M. Subfoveal choroidal neovascularization in a 3-year-old child with North Carolina macular dystrophy. J AAPOS 2007;11:614-15.

44. Bakall B, Bryan JS 3rd, Stone EM, Small KW. Choroidal neovascularization in north carolina macular dystrophy responsive to anti-vascular endothelial growth factor therapy. Retin Cases Brief Rep 2018; Oct 31 [Epub ahead of print].

45. de Carlo TE, Romano A, Waheed NK, Duker JS. A review of optical coherence tomography angiography (OCTA). Int J Retina Vitreous 2015;1:5.

46. Spaide RF, Fujimoto JG, Waheed NK, Sadda SR, Staurenghi G. Optica coherence tomography angiography. Prog Retin Eye Res 2018;64:155.

47. Tan ACS, Tan GS, Denniston AK, Keane PA, Ang M, Milea D, Chakravarthy U, Cheung CMG. An overview of the clinical applications of optical coherence tomography angiography. Eye 2018:32(2):262-86.

48. Ong SS, Patel TP, Singh MS. Optical Coherence Tomography Angiography Imaging in Inherited Retinal Diseases. J Clin Med 2019;8(12).pii:E2078.

49. Johnson AA, Guziewicz KE, Lee CJ, Kalathur RC, Pulido JS, Marmorstein LY, Marmorstein AD. Bestrophin 1 and retinal disease. Prog Retin Eye Res 2017;58:45-69.

50. Tsang SH, Sharma T. North Carolina Macular Dystrophy. Adv Exp Med Biol 2018;1085:109-10.

51. Tandon M, Barnett $C$, Taranath D. Case report: North Carolina macu lar dystrophy misdiagnosed as congenital ocular toxoplasmosis. Mol Vis 2019;25:731-33. 